\title{
The Existential Framework of Zentropa's Narrative
}

\author{
By Gabriel Giralt
}

Spring 2001 Issue of KINEMA

\section{THE EXISTENTIAL FRAMEWORK OF ZENTROPA'S NARRATIVE: A CLASH OF TWO NATIONAL IDENTITIES}

"... The difference between what you should be and what you are is something that means quite a lot to me. That's why idealism, or the idealist, interest me as much as they do".

Lars Von Trier. (Tranceformer: A Portrait of Lars Von Trier)

Lars Von Trier is considered by some film critics to be Denmark's most gifted director since Carl T. Dreyer. His highly technical and innovative style have brought him international recognition at prominent film festivals, including the most prestigious prize Palme d'Or at Cannes, which he received recently for his work Dancer in the Dark (2000). His innovative approach to narrative film is made manifest in his co-authoring and co-founding of "Dogma 95" a group intent on reforming mainstream aesthetics in order to return to a perceived lost authenticity in cinema. ${ }^{(1)}$ This reform was crystallized in a "vow of chastity" manifesto of ten technical mandates intended to provide the rudiments guaranteed to enable the filmmaker to capture reality in its own habitat without the artificial veneer of commercial cinema.

This new undertaking on the part of Von Trier is not considered to be entirely original. The reformative group, "Dogma 95", views itself as resuming the cinematic ideals put forward by the Italian Neorealists and the French New Wave. In some measure all of these movements, like "Dogma 95", are reactions against the superficial and seamless commercialized films of their day. However, unlike Von Trier's predecessors (i.e., the French New Wave) who acknowledge openly the influence of mainstream Hollywood in their work, Von Trier does not like to proclaim such an association, he seeks to distance himself from a cinematic style proper to the American cinema. ${ }^{(2)}$ Yet, in spite of his desire to establish this difference, he does manage to retain some of Hollywood's hallmarks in his own work. Zentropa (1991) is such an example. Its narrative resembles Hollywood's World War II films of the1940s in which Nazi Germany is demonized in a stereotypical and unappealing caricature as part of the nation-wide propaganda to rouse in both the American citizen and the GI soldier the will to fight against fascism. ${ }^{(3)}$

Therefore, this article is an attempt to show that Zentropa revisits in both its narrative and stylistic system, the war-like confrontation between Germany and America which prevailed in some of Hollywood's narratives of the 40s and 50s. But, unlike these earlier American films Zentropa seeks to make manifest in an existentialist phenomenological framework that the ideological socio-cultural climate that keeps Germany's idealistic and America's pragmatic attitudinal mindsets at odds with each other derives from the very psychosomatic bipolar structure of all human personality. In this regard the antagonistic climate of World War II is not ended, it is merely transposed to a more subjective battlefront inherent within each person's self-humanizing psychosomatic personality. This battlefront in Zentropa is the threshold between a person's inner subjective psychic utopian self and outer objective pragmatic self.

\section{Existential Framework}

In a 1998 satellite interview produced by the Canadian National Film Institute, Von Trier indicates that there is a common "thread" running through all of his films which ties them together. Remarkably, he does not spell out this common thread. He even seems completely uninterested and even unaware that his films, including Zentropa are staged within a phenomenological framework peculiar to existentialism. Furthermore, he manifests no theoretical interest in any subject, be it religion, political ideology or whatever. His entire attention seems to be placed in the development of a narrative tightly knit to a cinematic stylistic structure designed to achieve a vanguardist effect that emerges from all his films. Yet, to this student of his films, the actual common thread that ties them all together is in the core of his narratives unfolding from within existentialism's phenomenological analysis of human consciousness. It is the onus of this present article to make this case to the reader. 
Therefore, in order to comprehend the thought structure that sustains the existential framework of Zentropa's narrative, it will be helpful to introduce in short and in broad terms some of the existential premises that acts as the basis to this narrative study.

To this end, it can be said that Existentialism is a personalism whose beginning is traced back to the 19th century with thinkers such as Kierkegaard, and Nietzsche. It has become increasingly prominent in the 20th century with many noted advocates such as, Martin Heidegger, Albert Camus, Jean-Paul Sartre, Jose Ortega y Gasset, etc... Their number includes philosophers, journalists, novelists, playwrights, university professors, etc... What is peculiar to all of them is their manner of thinking and framing their thinking within a phenomenological context. Heidegger summed up this context with the succinct formula: "Beingin-the-World." Taken by itself this formula seems too abstract to convey any specific meaning. When it is sufficiently interpreted, it discloses the clue which binds together all of these existentialists.

Each and every individual is an instance of this "Being-in-the-World." That is, each person lives in a factual situation (i.e., his everyday world) with which he/she is occupied. The meaning of this world (i.e., its being) is not to be found in this world itself. The meaning (i.e., value and worth) of each person's world is freely identified by each person as he or she can decide for him or herself. Hence, each human is situated egocentrically in some factual occupation (his world) which is meaningless apart from the meaning (its being) which he or herself imparts to it. The world itself (viz., a housewife, a professional athlete, a factory worker, etc.), is the work which occupies an individual's outer self while the meaning, being, and value of this work derives from the individual's inner self. ${ }^{(4)}$

Quite simply this means that a professional athlete may be very successful but still dissatisfied with herself. In contrast a janitor may be occupied at a very menial job and very satisfied with himself. In other words, it is not one's occupational environment which is meaningful. Rather, it is one's attitude and self-esteem which imparts meaning to one's factual situation. Further, it is not an issue whether one is proficient or not in his factual situation. Rather, the meaning, value, and being of one's factual engagement is determined entirely by one's inner self-worth and self-estimation. Hence, one's awareness of one's cultural environment and one's occupation in this environment is not the same as one's awareness of one's inner self. One's outer somatic self and one's inner psychic self are simply two opposite poles of one's egocentric self-awareness.

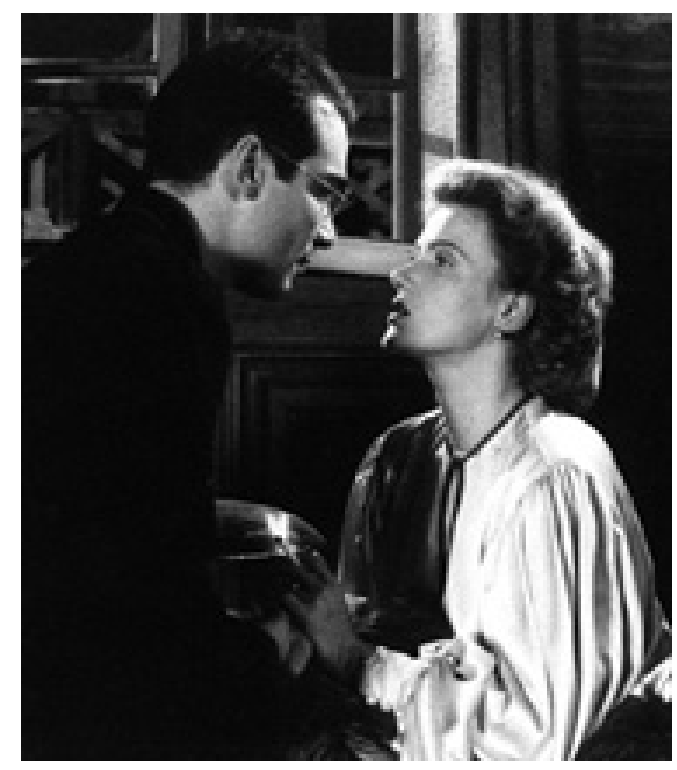

Figure 1: Zentropa (Lars Von Trier, 1991)

The world of one's outer self somatically engages one's body and is publicly observable by others while the meaning and worth of one's inner self psychically engages one's mind and thoughts and is unobservable to other than one's very own self. One's outer worldly self is realistic because one can feel one's body engaged in it. One is energetic, tired, emotionally upset or emotionally excited, etc... One's inner psychic self is idealistic 
because one cannot feel it. One's mind is absorbed in day dreaming about its own hopes and anxieties, etc. The existentialist regards these two polarized mindsets as two opposite sides of the same egocentric coin. Every human being is mentally idealistic and bodily realistic. Everyone dreams and everyone works. One's dreaming self is other than one's working self. Nonetheless, it is one and the same individual that is both conscious of his body somatically toiling in a work place and conscious of his mind psychically lulled to sleep in his day dreams.

Therefore, the pure idealist explains every aspect of culture in terms of abstract ideas the mind entertains while the pure realist insists that culture is developed only when such ideas are put to work to benefit one's bodily comforts. The existentialist insists that the mind and the body are interdependent. The mind's fictional conceptions and the body's factual contraptions are interlocked in each human's egocentric selfawareness and it is the phenomenological structure of every single human being. Every human person is caught up in an egocentric tension between his inner mental self and his outer pragmatic self. It is a paradox in as much as the inner meaning of one's life never dovetails with the outer situation in which one lives.

\section{Two Polarized Cultures}

Zentropa is definitely a depiction of Germany's fascist culture in stark contrast with the American pragmatic, capitalistic culture. The entire film is presented in black-and-white, and low saturated colour further reinforcing the viewer's grim experience of post-war Germany. The narrative's dramatic tension consists in highlighting the disparity and tension between the American mindset exemplified in both Leo and the American military officer, Col. Harris, and the German frame of mind exemplified in Max and Kate Hartman, Uncle Kessler, etc. Each is pitted against the other in an ideological bipolar tension in such a manner that neither one, in the final analysis, benefit from this comparison.

In this regard, Von Trier differs remarkably from the Classical Hollywood structure that clearly eschews ambiguity and ambivalence in that there is no confusion over who are the good and bad guys and what it is the final outcome. One always prevails over the other. Zentropa, on the other hand, has a moot ending in which neither the capitalistic nor the fascist mindset is an outright victor over the other. Zentropa succeeds in conveying to the viewer that victory on the battleground does not insure victory on the social ground where different cultural perspectives clash. By highlighting one cultural mindset in terms of its polar opposite, Von Trier succeeds in disclosing to the viewer the existential paradox and ambivalence inherent in mankind itself.

Therefore, Zentropa is to bring home a tension and confrontation between two diametrically opposite national life styles entrenched within the main character's psychosomatic personality, Leo. In the narrative, Leo attempts to become acclimatized to the German sociological ideology so strange and alien to his own American individualistic and pragmatic frame of mind. Hence, existentially and phenomenologically he is seeking to reconcile his American realistic self-awareness with his idealistic dream-like self-awareness which he is not entirely familiar. Of course, no matter how hard he tries, he always fails to reconcile.

This fatalistic irony is intrinsic to existentialism. Existentialism is fixated on the view that mankind is the master of its own fate precisely because each individual can by his or her own free-will transcend and escape his particular circumstances in life and determine for him or herself their own destiny, meaning, and being. But in the final analysis this is impossible precisely because one cannot fully and completely detach and isolate one's inner psychic utopian self from one's outer somatic self. This is the absurdity that the existentialist emphasizes. One can only find one's self by freely transcending one's own every-day world. Yet, this transcendence always ends in a climatic tragedy. This is the Greek myth of Sisyphus on which the existentialist, Camus, harps in his writings.

\section{The Narrative Compared}

Cinematically speaking, Zentropa has been described as a hodgepodge of intrigues reminiscent of Rossellini's visual narrative, Germany year Zero (1947). Both are marked by the pronounced devastation of a bleak and inhospitable landscape of German cities lying in ruins with people struggling to survive under subhuman conditions. ${ }^{(5)}$ Zentropa has also been compared to Reed's suspense action plot, The Third Man (1949), in which its main character, a young naive American, becomes unwittingly involved in a series of murders. ${ }^{6)} \mathrm{A}$ number of reviews have also compared this film with Hitchcock's Vertigo (1958) because of its labyrinthine thriller-like suspense and centrality of its sensually provocative femme fatale character. ${ }^{(7)}$ 
Granting these similarities, these reviews have failed to emphasize that Zentropa is a modern cinematic version of a recurrent Hollywood war theme of the 1940s in which American and Nazi German socio-cultural ideologies are in deadly conflict. Zentropa is a throw-back to the embattled climate that marks such American war films as Lifeboat, (1944) Berlin Express, (1949) and A Foreign Affair, (1948) among others. However, while their themes overlap, the Hollywood approach fails to introduce the viewer to the phenomenological dimension of existentialism inherent in Zentropa. It is the objective of this article to bring this home to the reader.

To better appreciate the in depth bipolar psychosomatic structure inherent in Von Trier's Zentropa, its thematic treatment of the ideological tension between Germany's fascism and America's democratic capitalism outreach will be compared with Hollywood's treatment of the very same theme inherent in Billy Wilder's $A$ Foreign Affair.

Wilder's A Foreign Affair introduces the disparity between the two antagonistic ideologies by contrasting two opposite lifestyles personified in the two female characters. One is emblematic of American pragmatism; the other characterizes German idealism. The American pragmatism is voiced by Ms. Frost (Jean Arthur), an American Congress woman and a fired up optimist daring to tackle any problem with an unbounded selfassurance and determination. Wilder introduces her in the narrative as she is flying on a mission with a small group of congressmen to investigate the low morale occurring among the American military occupational forces. Ms. Frost's pragmatic outlook and fix-all mindset are summed up in her opening dialogue:

"We are here to investigate the morale of American occupation troops; nothing else. 1200 of our boys are policing that pest down below and according to our reports they are being infected by a kind of moral malaria. It is our duty...to find the facts, and if these reports are true to fumigate that place with all the insecticide at our disposal."

It is quite clear from this introduction that Ms. Frost's approach to the problem is to simply find out the facts and to efficiently correct them in the same manner one would find out why a car engine is malfunctioning and have a mechanic repair it. In other words, her pragmatic outlook enables her to size up everything in purely mechanical nuts and bolts terms and to get control of the situation by reducing it to a technical problem. ${ }^{\left({ }^{8}\right)}$ This approach is contrasted with Ms. Frost's German counterpart, Erika Von Schlutow (Marlene Dietrich) once a mistress of an important Nazi party member and now a cabaret singer.

Wilder enables the viewer to get an entirely different insight into the so called moral indecency among the occupational troops through Von Schlutow song Black Market. ${ }^{(9)}$ The song reveals with plain cynicism what post-war survival in Germany truly means. -- That is, the exploitation of the German people by the so called US liberating armed forces.

"Black Market. Laces for the misses, chewing gum for kisses. Black Market. Cuckoo clocks and bangles, thousand little angles and see my little music box today. Only six cartons, want to hear play? Black Market. Mind and microscope for liverwurst and soap. Browse around, I've got so many toys; don't be bashful; step up boys. You like my first edition, its yours -- that's how I am -- a simple definition: You take art, I take spam. To you for your K-ration, compassion -- and maybe an inkling, a twinkling of real sympathy. I am selling out. Take all I've got. Ambitions, convictions, the works, why not? Enjoy these goods. For boy! These goods -- are hot!"

The lyrics convey the real situation with a poignancy that transcends Ms. Frost's utilitarian outlook. Wilder's juxtaposition of the two antipodal feminine personalities brings home to the audience the double standard of the American approach inherent in the military occupational forces. On the one hand, they are attempting to maintain law and order. On the other hand, they are flagrantly disregarding the most basic conduct of moral decency. ${ }^{(10)}$

Ms. Frost's and Von Schlutow's antipodal approach to the military troops' morale decay is obviously very different. One approaches the problem quite objectively as though it were merely a matter of behavioural adjustment. The other approaches the problem subjectively as an issue involving one's mental attitude. The American account is technically functional and empirically factual while the German one acknowledges a non-tangible and non-empirical dimension involving one's life style and in which the beliefs, ideals, and social values of Germans are being traded off for the tidbits American troops can provide in exchange for them. 


\section{Zentropa's Narrative Exploration}

Von Trier in Zentropa addresses this same ideological divide separating Germany from America. Unlike Wilder, however, he delves more deeply into the human psychosomatic, egocentric self to dramatize the very threshold that allows the viewer to subtly cross over from one cultural context to the other. In other words, he does not touch on the two opposing cultures superficially as is the case in Wilder's narrative. He allows the viewer to probe into the depths of the two antagonistically polarized cultures by engaging them phenomenologically from within the egocentric, existentially charged self-consciousness. In this case, it is one and the same individual Leo, who tries to bridge and reconcile within himself this ideological divide separating fascist Germany from capitalist America.

Von Trier's approach enables the viewer to appreciate that the element of alienation is not confined to the American's experience of and encounter with Nazi Germany. It is not only the German culture that appears alien to the Americans. The American culture also appears just as alien to the Germans. The element of self-alienation is reciprocally inherent in both approaches since each culture itself is polarized vis-à-vis its counterpart. Von Trier accomplishes this disclosure of the reciprocal cultural alienation by introducing the viewer at the very opening into the utopian dream-world of the German point of view by the medium of a hypnotic trance. The main character in Zentropa is the American, Leopold Kessler (Jean-Mark Barr), who under this hypnotic trance makes his entrance into the dream-like world of Zentropa, a railroad enterprise under the control of a state-owned and state-managed establishment. Within this dream-like world everything and everyone, Leo included, are subject to a hidden, overbearing, bureaucratic and repressive mastermind control that affects everything and everyone involved in the railroad's operation.

This dominating bureaucratic cultural environment is underscored in the narrative when Leo and his uncle Kessler (Ernst-Hugo Jaregard), a conductor on the railroad, Zentropa, introduces the former to his new job on the railroad. Uncle Kessler reminds his nephew that as a new employee on the railroad he should be mindful that the uniform he will be wearing ... "is the property of the company but paid for by the employee..."Uncle Kessler's statement makes it poignantly clear to Leo that both his job and his attire are the property of the state's collectivity and not his own private possession. This statement itself reveals the radical difference between Leo's American capitalistic cultural outlook and that of the German concern for society's collective socialist welfare. ${ }^{(11)}$

The ideological polarization between German and American mentalities is further personified in two antithetical personalities. The one is Max Hartman (Jorgen Reenberg), a German bureaucratic magnate who is mostly introspectively self-absorbed with the overall management of Zentropa's railroad system. He is unquestionably an introvert. The other is that of Colonel Harris (Eddie Constantine), an American military officer who is much the extrovert, always alert to any contretemps which would impede the progress of Germany's de-nazification and rehabilitation.

To Max, the German utopian socialist society is much like a model railroad. The more harmoniously, and perfectly a society functions like a model railroad, the more it attains its ideal of perfection. This is revealed by his daughter, Kate Hartman, (Barbara Sukowa) as she speaks to Leo of her father, as one who sees "Germany as his own model railway running round and around." She spells this out to Leo as she points to a small scale model train railroad that her father keeps in one of the upstairs rooms.

To Colonel Harris, the American pragmatist, society is not measured by its performance in view of some abstract utopian model. It is more of a rough-and-tumble capitalistic enterprise undertaken by many different individuals. Such a multi-partisan undertaking makes for considerable complexity and requires repeated intervention and adjustment to be able to function well. He perceives Max Hartman's idealization -- as Max is seen to be frequently standing aloof staring out the window for hours waiting for the 9:15 train to come by at precisely the stroke of the quarter-hour -- as a pitiful and inscrutable figure.

This disparity between the two is further illustrated in the film's narrative as we see Colonel Harris deal with "the policy of de-nazification" of Germany. The Colonel attempts to keep his friend Max, a former Nazi and magnate of Zentropa, the railway system that transported millions of Jews to extermination camps, as the continuing mastermind of the railways that are vital in rebuilding Germany's future. From the Colonel's point of view, Max is the only individual who has the know-how to oversee and manage the railroad company. In order to accomplish his objective, the Colonel works out a deal with a Jew (played by Von Trier himself) 
to testify in Max's favour in order to hide his long list of war crimes.

\section{Irony and Polarized Tension}

This part of the narrative underscores the irony of the American colonel's pragmatic mindset completely oblivious to any moral consideration interfering with keeping Max on the job. At the same time the colonel's action brings to light a historical fact; the same high officials responsible for war crimes against the Jews, become themselves architects of Germany's rehabilitation and renewal. ${ }^{(12)}$

To further expand and exemplify the reciprocal tension between Germany's idealism and America's capitalistic realism the narrative highlights the polarized tension between the American, Leo, and his German uncle, Kessler, the railroad's conductor. The American is confronted with keeping to the absolute letter the railroad's stringent regulations and meticulous multiplied steps in tending to the passenger's needs.

All of these inflexible and demanding minutiae make manifest the mind-boggling frame of mind of the fascist mentality which cuts against Leo's freewheeling American mindset. The narrative brings this forward when Leo is scolded by his uncle who insists that the shoes not merely be polished but must also have the compartment number of their owner written on their soles as evidence of this work having been carried out. Leo refuses to accept such a ridiculous and superfluous task. He considers it foolish that the chalk mark and not the polished shoes themselves be evidence of his work.

(Uncle Kessler)

"...Check mark! A check mark on the sole is the guarantee that these shoes have been polished; and that they have been polished by the conductor of the car."

(Leo)

"I can't see how the check mark can be the passenger's guarantee of anything."

(Uncle Kessler)

"No! No! You have come here with your background, an American culture, an American way of thinking. But, I ask you kindly, kindly, "Herr Kessler", without humility you will not go anywhere...Besides, the check mark also indicates the traveller's compartment. Take these shoes for example... where do they belong?"

(Leo)

"Now, I lost track."

(Uncle Kessler)

"No! No! There you are. And how will you find out?"

(Leo)

"I can always ask one of the passengers."

(Uncle Kessler)

"When I'll return I want to see all the shoes marked with compartment numbers. And under no circumstances will I tolerate any disturbances of the passengers."

The incident becomes a subtle metaphor highlighting the remarkable tension and polarization separating each respective mindset and personality vis-à-vis the other. On the one hand, the fascistic perspective cannot brook any deviation from a society that functions in lockstep with its introspective vision of a perfect model safeguarded by a bureaucratic committee vested with the authority to oversee and regulate everything. On the other hand, the pragmatic mindset is not involved with any such vision. Societal matters are worked out at the lowest level of those immediately involved with servicing people's needs. To one frame of mind, uniformity overrides any deviation, while to the other mindset diversification overrides any concern for uniformity and regulations. In the German fascistic view, the social contract demands that all agree to agree to get along together in a uniform way without deviation. The moral issue is not so much concerned with what is right or wrong. It is more concerned with everyone agreeing to get along with everyone else. Without uniformity bureaucratically supervised, there would be no such social agreement. On the other hand, from the American pragmatic view, the social contract 
demands that all agree to disagree. That is, the "social contract" is one of individualism and individualistic initiative. All are of "one mind" that each individual is entitled to his own opinion providing it does not interfere with the other's differing viewpoint. ${ }^{(13)}$

If we compare Leo and his German uncle's ideological confrontation with the two woman from Wilder's $A$ Foreign Affair, Von Trier has his two antagonists confront each other phenomenologically within one and the same egocentric existential inter-subjective self-awareness whereas the two women in Wilder's narrative merely meet in juxtaposition but not in a phenomenological inter-personalized tension. Hence, neither of the two stereotypical characters of Wilder's film engage the other in an attempt to transcend each one's own cultural point of view and empathically embrace the other's antipodal viewpoint. Hence, neither woman is able to transcend her own cultural habitat and environment.

\section{Interpersonal Subjectivity}

Von Trier's phenomenological approach introduces the viewer to an interpersonal subjectivity that is very much the hallmark of existentialism. Each person's psychosomatic personality consists of an inner phantom psychic self and an outer observable somatic self. This interpersonal egocentric subjectivity is not optically available to the camera's lens. The outer-face of this egocentric self is quite visually available in a mirror's reflection. In other words, the camera can capture the character's facial expressions and bodily gestures, but the mindset, attitude, and psyche, remain hidden to the camera's eye.

So, how does Von Trier cinematically overcome this dichotomy between one's somatic surface visualization and one's subsurface psychic non-visualization? He does so simply by allowing the American, Leo, to be self-hypnotized and to sink into the subconscious depths of his own psyche in an hypnotic trance induced by a faceless voice off-screen that invites the viewer along with Leo to be carried away into this psychic depth. When he awakens within this dream world he finds himself in the strange underworld of Zentropa which is Germany in its aftermath of its defeat in World War II. In Wilder's narrative, on the other hand, the German utopian culture remains always alien to an American audience since they cannot see the inner self of the character's psyche or frame of mind. This is hidden within one's introspective self-consciousness beyond the camera's empirical tactual scrutiny. Wilder's A Foreign Affair stylistically represents the German culture's own moral degradation and demoralization. But only on the surface; and, not in the depth of its own inner egocentric subjectivity. The audience interest is merely superficial as the narrative development remains within the behavioural reach of the camera's superficial optic reach that cannot penetrate beyond the surface of a mirror's facial reflection.

Von Trier's phenomenological exploration of the subjectivity proper to one's psyche and inner self allows the audience to enter into the depth of the cultural divide that separates the civility of the socialist from that of the capitalist. This is the principal difference between Wilder's superficial unidimensional Hollywood narrative and Von Trier bi-dimensional subsurface treatment depicting post-war Germany.

This psychosomatic bipolar consciousness bonded together as subsurface and surface is very much in the way that a mirror is the glass' reflection of one's facial features made possible by a black subsurface placed behind a clear glass surface. If one gazes at the mirror's surface one can see the reflection of one's own face in the mirror. If, on the other hand, one looks at the back of the glass and at its black subsurface behind the mirror one becomes aware of one's self seeing nothing at all but a barren blackness of any and every facial reflection other than, possibly, a trademark logo indicating the mirror's manufacturer. One is not conscious of one's own facial reflection in the act of looking at the mirror's black backside. One is self-conscious of not seeing any face at all as was the case on the other mirror's translucent side of the glass. Hence, one becomes quickly conscious of one's very own 'subsurface' faceless psychic self gazing as in a stupor into empty space. Both one's surface and one's subsurface egocentric self are interlocked together as is a sheet of glass that is transparent on its surface side and opaque on its subsurface side.

Von Trier cleverly and skilfully plays the psychic subsurface against the somatic surface in order to present what cannot be encountered with the camera's eye alone. An example, again, of his skill in engaging in this phenomenological context in his films is this encounter of Leo with his uncle in polishing the passenger's shoes. This encounter contrasts and pits the one ideological egocentric subjectivity with the other in an inter-subjective give-and-take, making manifest each one's hidden psychic mindset and mental orientation. 


\section{Inner and Outer Reality}

Von Trier explores the inner subjectivity of his principal characters and exposes cinematically this psychic dimension in polar tension with their outer objective observable behaviour that the camera can readily observe. This psychosomatic polar tension is presented in a background-foreground egocentric grounding. And the viewer is enabled to enter this drama as though it were unfolding experientially within his very phenomenological bi-polar self-consciousness.

Hence, the main character's outer action plainly captured on camera are not the focus of the film's drama. Rather, they disclose and point to an inner subjective reality hidden to the camera's eye. And it is this inner psychic reality that becomes for the viewer the real centre of the film's drama. In other words, the 'subsurface' of one's self-awareness (i.e., a person's mental framework, outlook, socio-political bias and religious or nonreligious commitment) is much more important and intriguing to Von Trier than is the mere 'surface' phenomenal appearance of Hollywood's films. This existential 'subsurface' is captured in the film through the dialogue itself, aided by stylistic attention to mise-en-scene, cinematography, sound, etc.

\section{Cinematic Roots}

Von Trier's phenomenological inner subjective approach is typical of the European Cinema interest in the psychic dimension of the human person. This approach is not entirely unfamiliar to such films as Rossellini's Germany Year Zero (1947) and Godard's Germany Year 90 Nine Zero (1991), both dealing with the theme of post-war Germany. A study of these films is beyond the scope of this paper. Nonetheless, a few comments are in order. Rossellini's presentation of the horrors of post-war is a realism that transcends the mere surface of reality.

The action of this film engages the fortunes of a family consisting of Edmund, Eva, Karl Heinz, and their father. They are victims of a post-war, dehumanizing environment to which they all eventually succumb and perish. Rossellini's outward events (realism) are a mere pretext to reveal an inner forum..

In somewhat similar manner Godard takes a similar film journey, this time forty-five years after the war, to explore what was left after the removal of the Berlin Wall in 1989. Godard resurrects Alphaville's Lemmy Caution (Zentropa's Colonel Harris) to survey a socio-political landscape scarred by the ravages of the Cold War. In this film Godard traces his own ideological journey recognizing "that where one lives is less important than how one lives, and that how one lives is a matter of calling for unending thought, negotiation and self-scrutiny." (14)

Zentropa, like Germany Year Zero and Germany Year 90 Nine Zero is a narrative in which the phenomenological inside-out exploration of the in-depth dimension of the person's hidden subjectivity looms very large. This existential in-depth concern is completely overlooked by the Hollywood approach in depicting this same socio-political climate of Germany's post-war period. Hollywood seems entirely captivated by what phenomenally appears on the surface of one's personality.

These two contrasting interests, the phenomenal and the phenomenological, typify two opposite cinematic forms of expression as well as two different film form traditions. One, the Traditional or Classical Hollywood narrative: a pervasive objective and superficial representational style in depicting ideological conflict. The narrative presents a particular pattern of organizational structure that dominated Hollywood's mode of narration from 1917 to 1960. ${ }^{(15)}$ The other, the Non-Traditional or European narrative: a more introspective and therefore more inner subjective in seeking to express the more intangible and allusive ideological factors that are at the core of national cultures. This kind of narrative presents an internal formal organization that stands in opposition to the Hollywood structure; historically a descendant of the early European Avant-Garde cinemas: German Expressionism and French Impressionism. ${ }^{(16)}$

The difference between the two stems from the interpretation and comprehension of the narrative that cannot take place apart from its contextual significance which issues from the director's own frame-of-mind. This frame-of-mind is in itself realistic or idealistic. In the context of A Foreign Affair, a realistic narrative, it separates the American realist from the German idealist into two clearly defined entities. The narrative peers outwardly to a tangible and visible reality. Its rhetoric is objective and highly visceral in speaking of the conflict. In Zentropa's narrative, on the other hand, the two antagonistic entities are, at times, no longer separate groups but a conflict between the two, "good" and "evil", "emotional" and "rational" temperament 
set within the main character. The narrative is introspective and looks inward, psychically to its reality. The rhetoric is highly subjective in speaking of the conflict.

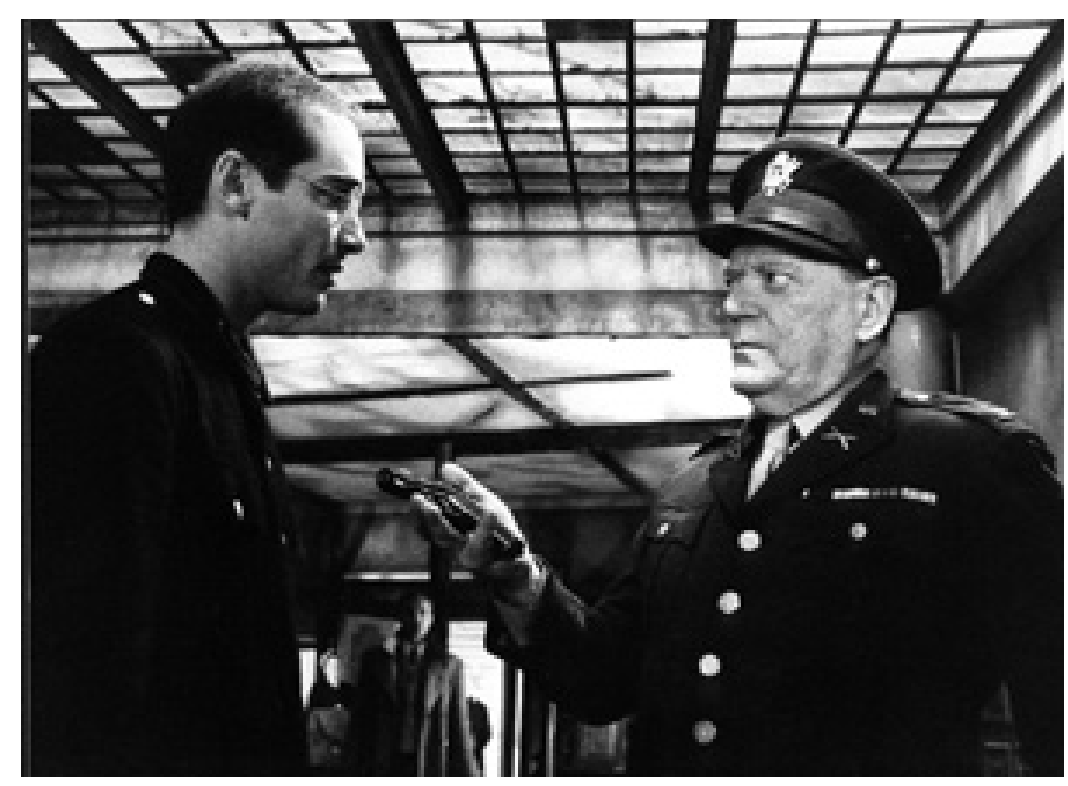

Figure 2: Zentropa (Lars Von Trier, 1991)

In Zentropa there is no clear-cut demarcation between the German and American cultural ideologies. Each is interlocked with the other. The opposing cultures are viewed and approached as being interconnected to each other in an existential bi-polarization. This can be illustrated in Kate's characterization. She is presented as personifying both an emotionally sensitive and sensuous woman typical of Hollywood's focus on the human body exhibited in erotic action. This is the Kate who tries to seduce Leo. But she also displays the other psychic side of herself which is decidedly unemotional, insensitive, cerebral, calculating, and fully detached. This is the Kate who is a member of the German secret underground movement, the Werewolf.

Von Trier successfully integrates the outer body's palpable sensuality with the inner mind's imperceptible and cerebral in the same manner he blends two cinematic discourses, the Hollywood and the European. That is, he is able to articulate a traditional narrative structure of cause/effect system based on appointments and deadlines and at the same time remaining predominantly inner-subjective and ambiguous.

\section{Two Narrational Devices}

Ironically enough, some of Zentropa's narrative ambiguity spins around two common narrational devices easy to find in the classical Hollywood war film: the off-screen narration and the back projection.

Zentropa's off-screen narration begins at the very opening of the narrative introducing both the audience and the film's main character, Leo Kessler, into the dream-like world that is the culturally demoralized climate of post-war Germany. The viewer is subtly lulled into a hypnotic trance by the clickety-clack sound of a train moving along the railroad-tracks and the faceless voice (played by Von Sydow) to encounter what turns out to be Leo's entrance into the dream world.

"...You will now listen to my voice. My voice will help you and guide you still deeper into Europa... Every time you hear my voice with every sound and every number you will enter still deeper there, relaxed and receptive...I shall now count "one" through "ten"... At the count of "ten" you will be in Europa...I say "one"... and as you focus your attention entirely on my voice you will slowly begin to relax. "Two," your hands and your fingers are getting warmer and heavier. "Three," the warmth is spreading through your arms to your shoulders and neck... "Four," your feet and your legs are getting heavier. "Five," the warmth is spreading to the whole of your body...On "six" I want you to go deeper...I say "six" and the whole of your relaxed body is beginning to sink... "Seven," you go deeper and deeper and deeper... "Eight," on every breath you take you 
go deeper... "Nine," you're floating... On the mental count of "ten," you will be in Europa...be there at "ten"..."

Leo, who awakens within this psychic depth of inner subjectivity does not awaken into his familiar bodily experiences. Rather, he awakens within a cultural world of experiences, the German culture. Zentropa's off-screen narration (voice-over) deepens into subjectivity as it forwards ambiguity by opening up a spatial and temporal narration of peculiar characteristics. This apparently omniscient and ubiquitous off-screen voice differs from the Hollywood narrator in that it does not speak up for the main character, nor does he speaks outside of the narrative space and time complementing narrational information. A case in point can be taken from the opening of Berlin Express, which begins with the main character narrating a series of events guiding the audience in the interpretation and comprehension of what is seen on the screen. The off-screen voice is immediately identified with one of the film's principal actors.

In Zentropa the off-screen voice assumes the role of an invisible character interacting with the main character as he becomes an agent for change in the unfolding of the action in the narrative. This interactivity between voice-over and character, in the off-set of the narrative, establishes at one level a spatial narrational conflict that places the faceless voice in some undetermined location. At another level, it furthers the ambiguity making us wonder as to which space is concrete and temporally sound in the narrative. Is Leo's experience fictional, created in his imagination by hypnotic suggestion or is it recreated as he remembers past-experiences? Whatever the case may be, if we assume that the off-screen voice is to be in present time, the main story of the film becomes a visual representation of Leo's subjectivity that takes us in two different directions. One, where the character's engagement is a pure illusion. Leo's conflict and interactivity with the other characters are all taking place in Leo's mind. The other, the undetermined space, the off-screen space, where the faceless voice resides is where the real Leo exist. Consequently, Leo's experience of post-war Germany is nothing more than an illusory reality where he imagines himself in. However, if we take the faceless voice to be the works of Leo's fantasy, the ambiguity runs even deeper. Leo's life experience in Germany still remains an illusion since we cannot justify hearing Leo's inner voice being played in his mind after his death. The number of temporal and spatial possibilities that can be tagged to Max von Sydow's mysterious voice is endless.

This ambiguity played at the expenses of the character's subjectivity can also be seen with the usage of the rear-screen projection. The rear-screen projection forwards ambiguity as the narrative employs this Classical Hollywood technique that amplifies and extends the on-camera shot's spatial logistical limitation into one single unified space. The on-camera shot is shaped to match exposure, lighting schema, visual perspective, etc ... of the projected shot (rear-screen projection) aiming for acceptable realism. Through this classical Hollywood illusory space A Foreign Affair Colonel Plummer takes the Congressional delegation in a tour through the devastated city of Berlin, driving by the Reich's Chancellery( where Hitler married and later died with Eva Braun), the Adlon Hotel, the Unter den Linden, and the Tiergarten. ${ }^{(17)}$

Zentropa incorporates this narrational device to cancel its realism and make it a purely aesthetical choice. The Hollywood convention is set to interact with the background rear-screen projected action and vice versa. A good example of this technique can be taken from Leo Kessler's first encounter with Kate Hartmann. The entire exchange in the scene between Leo and Kate, is sustained by dialogue with Leo placed in the foreground on-camera (colour photography) and Kate, in the background on rear-screen projection (black and white photography). The visual representation or character placement is reversed in the second half of the scene ending with Leo now in rear-screen projection and Kate on-camera. This highly orchestrated space construction between on-camera (colour) and rear-screen projection (Black and White) is carried out with an extreme precise mirror like illusion. It creates not only, a visual dialectical tension between foreground and background questioning the illusion of a three dimensional world in a two dimensional plane but, it constructs a spatial dichotomy, a metaphor for the inability of the two unreconciled ideological positions to coexist in one and the same space.

Zentropa's subjective spatial expression created by the rear-screen projection sets also a correlation reminiscent of the narrational space that once was the trade mark of German Expressionism. While early German films achieved an illusory three dimensional background through purely graphical depiction, Zentropa manages to reach a comparable effect through purely cinematographic terms. However, Von Trier's relation with 
this early European film tradition does not end here, it is further affirmed as the film recreates a similar subjective narrative. Like its predecessor, subjectivity is articulated around the principles of ambiguity, self-reflexivity and authorial expression. These principles spring up from the film's narrative organization.

\section{Character's Mind}

In Zentropa the narrational polyphony created by the character's voices in the film is of a particular kind. Aside from the hypnotic faceless voice resounding inside Leo's consciousness, there is no direct access to the mind of the characters, neither from the part of the viewer or from the characters themselves. The inability to enter inside the characters mind is clearly expressed by the frustrated American Colonel Harris who is unable to understand or comprehend the post-war attitude of the Germans around him. "We bombed you to pieces and yet you all behave as if never was any war at all". The Colonel makes the audience aware that to gain entrance to the characters' internal world is by means of external knowledge, through their dialogue and their actions. In A Foreign Affair for instance, we tend to believe and accept at face value what we see and what we hear. If a character leads us into a wrong path by he/she not acting truthfully, we soon will be told and the case is clarified. In A Foreign Affair, we are told that Captain Pringle is lying about his love for Mrs. Frost. We find later that this is nothing more than a little narrative stratagem to bring about a satisfying twist at the end. Therefore, on the one hand, in A Foreign Affair, the unrestricted narration provides certain transparency with the narrational voices allowing us to check and verify what is being said or proposed. On the other hand, in Zentropa that is not the case. We doubt and we distrust the characters. What the characters say and what they end up doing are two different things. Zentropa's restricted narration does not provide room for such verifications. The ambiguous discourse makes us wonder why the characters act in the way they do, questioning the validity of what they say or do as well as their motives.

The narrative also poses other credibility problems as it introduces its characters and establishes their roles in the plot. In this game of inconsistencies, Leo's ambiguous situation of being an American in a German culture becomes the mark of Von Trier's narrational approach of highlighting one cultural perspective by offsetting it with another. This offsetting is accomplished by having both frames of mind emerge intrinsically within one and the very same egocentric self-conscious individual. This is accomplished phenomenologically because Von Trier seems to recognize that every person's self-consciousness is itself egocentrically grounded by a subsurface and a surface.

In other words, it is like a photograph of a human face. The face is visible in the photo but the back of the head is not. It is hidden. Even if one flips over the photograph, one cannot see the back of the head. Yet, one can conceptually be aware of it. Accordingly, one's egocentric consciousness itself has an outer side which is aware of its own body's somatic feelings and movements which can be photographically observed. This same consciousness also has an inner side which is aware of its own mind's psychic thoughts and motives which cannot be photographically observed. It is precisely within this phenomenological structure of one and the same individual self-consciousness that Von Trier integrates the American and German ideological cultures.

\section{Conclusion}

Consequently, Von Trier's artistic and aesthetic manipulation makes the film a mental experience rather than factual one. The film's cinematography invites the viewer to an in-depth perception of the overall context of war rather than focussing on the details and actions of a possible realistic representation of the conflict between the two ideologies. Therefore, the film is more of a narrative of what is imperceptible and hence, presumptively more subjective. In this manner, Von Trier implicitly imprints in the narrative an authorial commentary that differs from Hollywood's rhetoric: that the world created by the narrative and how this engages the viewer is strictly dependent on the director's subjectivity and the viewer's interpretation of it. This is in sharp contrast with Hollywood war films, realist in essence, where war issues are anchored upon concrete objective representational reality.

Zentropa's presentation of the ideological dictum, although free of propagandistic elements, does not quite free itself completely from Hollywood's war representation. The narrative does incorporate Hollywood's didactic aspects of "How" and "Where" these two ideological rivals differ. However, the film does not quite imitate Hollywood's bipolar ideological theme: the portrayal of the American Armed Forces as keeper of order and the Nazis as unreasonable and ill-behaved psychopaths. Von Trier makes them both appear as villains, denouncing both ideological outlooks: German Idealism and American pragmatic approaches to problem 
solving results in a communication failure between the two that goes beyond the language barrier, revealing that ideological solutions cannot mend the complexity of culture. In this dual ideological absurdity, Von Trier targets the dehumanized and obsessive punctilious orderliness of Nazi Germany with the characterization of Max Hartman and Uncle Kessler, as well as the naiveté of the American mentality with the characterization of Leo Kessler and Colonel Harris who strives to "free" the German culture of its inherent self-dehumanizing idealism and nationalism. This American "do-good" mentality is also mirrored in the characterization of Leo as he portrays the American gallant who seeks to "liberate" and "free" the German culture from its grief by bringing his own "free" and "uninhibited" casualness and innocence which actually leads him to selfdestruction. It is precisely this Hollywood portrayal of the Americans as "good-at-heart" that the narrative brings in this fatal end.

Von Trier's subjectivity, therefore, follows in the vein of the French existentialist writers. The characters in their narratives begin with the self and ends with the self. The dramatic epicentre radiates a fatalistic quality as the characters are unable to transcend their self-sealed egocentricity. In Von Trier particularly, it is a confrontation between two polar subjective views. However, their subjectivity, like in the case of the French existentialist, becomes an end in itself. It is a suicidal and/or destructive experience as the characters, unable to transcend their own subjective views, remain both alien to themselves and alienated from others. Therefore, Von Trier's fatalism is rooted in a subjectivity whose bipolarity remains completely antipodal and antagonistically alien and alienated.

Von Trier's ideological polarity is symptomatically spelled, since he does not fully address the very core of fascism or capitalism, nor of idealism and realism. He does not engage explicitly in a philosophical discourse with any of his characters. In fact, all the characters are symbols of their own ideology but not one of them is fully aware of the ideology in which he or she is imprisoned. However, although it is possible that Von Trier himself remains "in the dark" about what is crucial and what constitutes the very nucleus of these ideologies, their core beliefs and premises, he successfully manages to contrast and expose the idiosyncrasies of these two opposite cultures in a very remarkable manner.

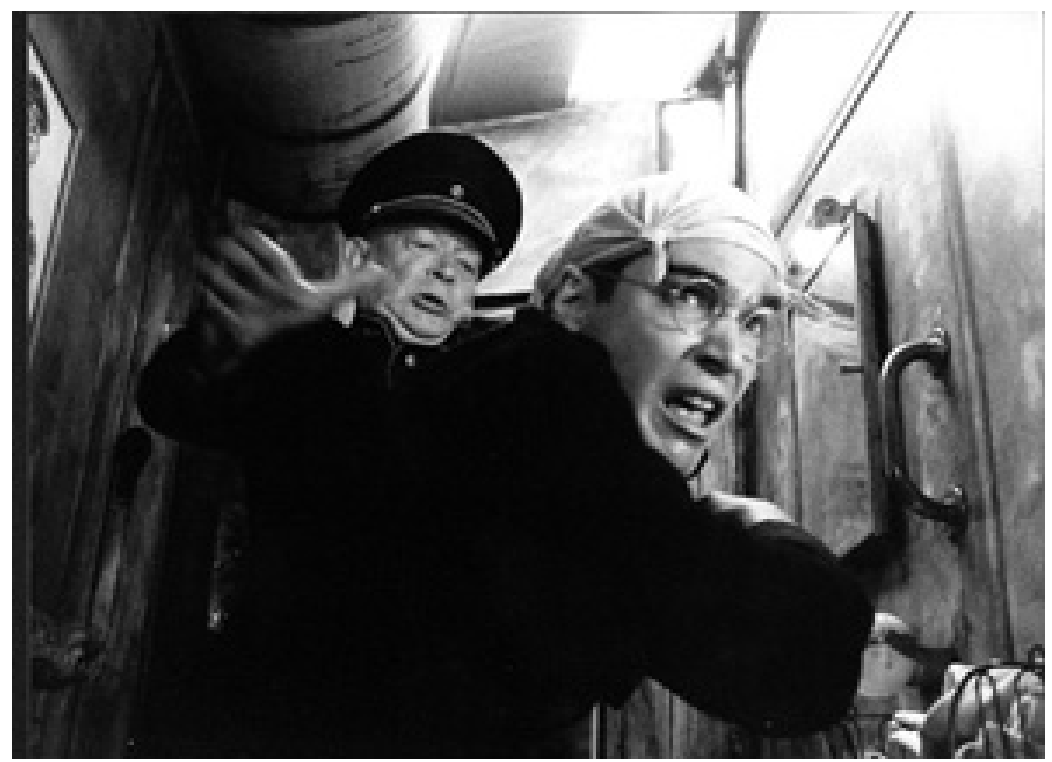

Figure 3: Zentropa (Lars Von Trier, 1991) 


\section{Notes}

1. Falcon, Richard. "European Cinema" Sight and Sound 2. No 1 (1999): 10-103.

2. Wayne, Richard "Still Waving Not Drowning" Sight and Sound 59. No. 3 (1990): 201-202.

3. Phillip L. Gianos, Politics and Politicians in American Films. (Praeger. Westport, Connecticut, 1998), 117.

4. Hubert L. Dreyfus, Being-in-the-World. A Commentary on Heidegger's Being and Time. (The MIT Press, Cambridge, Massachusetts, 1991).

5. Hoberman, J. "Strangers on a Train." The Village Voice 37. No. 21 (1992): 64. Strick, Phillip. "Europa." Sight and Sound 2.1 (1992): 47-48.

6. Corliss, Richard. "The Third Man Scheme." New York Times 8 Jun. 1992: 90-91. Richalson, Janice. "Zentropa." Cineaste 19. 2-3 (1992): 62-63.

7. Danton, Amina. "Leo et les loups." Cahiers du Cinema 449 (1991): 34-35. Dubeau, Alain. "Europa; un train, une metaphore, un film." 1 May 1997. http://www.horschamp.qc.ca/9705/critique/europa.html.

8. Kenneth Westphal, ed. Pragmatism, Reason $\mathscr{G}$ Norms: A Realistic Assesment. (Fordham University Press, 1998), 1-14.

9. "Black Market" together with "The ruins of Berlin" and "Want to Buy Some Illusions?" were written and composed by Frederick Hollander.

10. Robert Moeller, ed. West Germany Under Construction: Politics, Society and Culture in the Adenauer Era. (The University of Michigan, 1997), 78-80.

11. There are two opposed antagonistic poles: collectivity, on the one hand, and individualism, on the other. It is an issue of one's personalized self-possession and self-control. Collectivity (viz., fascism, nazism, communism, etc.) is based on the view that the "state" (i.e., a collectivity of individuals) is the guardian and safeguard of its citizens. Individualism (viz., capitalism) is based on the view that it is the individual citizens that safeguard the state. In a collectivity there is no individualistic ownership (i.e., private property) while in individualism there is no state ownership (i.e., public property) of the means of production. Hence, in a collectivity there is no inherent competition between workers, managers, and owners; there is no incentive for such factors to compete with each other. In an individualism there is every incentive for these factors to compete with each other. Hence, while in the one case the "public interest" is the elimination of all private ownership, in the other case the "public interest" is the elimination of all public interference in private ownership. But in either instance there is a "common good" transcending this "public interest" which is antagonistically opposed to each other.

12. Colonel Harris' "questionnaire" revealed Max Hartman guilty. However, the questionnaire prove later to be manipulated and the truth hidden to serve the American interest. The narrative seems to allude to a "131 point questionnaire", implemented in the American Zone, designed to test and evaluate in depth the degree of collaboration of the German population with the Nazi party in order to identify and eradicate any fascistic roots that could interfere with the normal process of building a new democratic Germany. Historically the program turned a total fiasco. Tom Bower. The Pledge Betrayed. (Doubleday \& Company Inc., 1982), 146.

13. The "Social Contract" proper to Rousseau (and others who are his contemporary in the age of the Enlightenment). The traditional understanding of "nature" (including human nature) is construed to be inimical and not beneficial to mankind. What occurs "naturally" is outside of the reach of mankind's own "control." Hence, man living in a "natural" environment cannot control his life; he is at the mercy of the elements. Rousseau reversed this. He brought about that it is more "natural" for man to take charge and control of everything in his own life and in his environment. By this revolutionary revision of "freedom," man is free to determine for himself what is natural and unnatural. There is no longer a " natural law" to which human nature is morally obligated to abide by. Hence, it remains for different human individuals to "decide for themselves" what is morally right and wrong. This is done by agreement; that is a consensus. This is the new "social contract" that underlies any and every political regime. Agreeing to agree is socialism; all must 
be like-minded. Agreeing to disagree is capitalism. Each individual has a right to his own opinion; this is pluralism. In either case, everything is relative to one's agreement.

14. David Sterritt, The Films of Jean-Luc Godard: Seeing the Invisible. (Cambridge University Press, 1999), 245.

15. David Bordwell, Narration in the Fiction Film. (University of Wisconsin Press, 1985), 156.

16. Ibid., 228-233.

17. Ralph Willet, The Americanization of Germany 1945-1949. (Routledge, N.Y., New York, 1989), 31.

\section{Author Information}

Gabriel GIRALT is Professor of Communication at the University of Akron (Ohio). He has presented academic papers nationally and internationally and has won several awards in Film and Video festivals. 